\title{
TRADUÇÃO E RECEPÇÃO: TEXTOS DRAMÁTICOS TRADUZIDOS POR MACHADO DE ASSIS
}

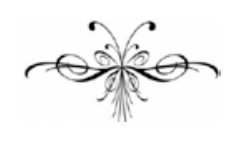

\author{
HELENA TORNQUIST
}

\begin{abstract}
Resumo: A força da tradução como elemento de mediação entre sistemas literários distintos é observada na atuação de Machado de Assis como crítico e tradutor de teatro no período em que iniciava sua carreira de escritor. Destacando alguns dos procedimentos adotados pelo autor para adequar ao público de sua terra, textos destinados originariamente às plateias francesas, evidencia-se aqui a força agregadora da tradução em uma literatura em processo de consolidação.
\end{abstract}

Palavras-chave: Tradução; Recepção; Comédia francesa.

\begin{abstract}
The strength of translation as mediator between distinct literary systems is highlighted by Machado de Assis' works in drama criticism and translation, especially in the early years of his career as a writer. In addition to advance some of his strategies to adapt text that was originally meant for the French, there evidence of an underlying belief that translation represented an aggregating power for the then consolidating Brazilian literature.
\end{abstract}

Keywords: Translation; Reception; French Comedy.

Traduzir, editar uma tradução não significa apenas se ocupar com uma operação de natureza linguística, é também tomar uma decisão que põe em jogo um equilíbrio cultural e social.

Yves Chevrel

$\mathrm{E}$ m decorrência do desenvolvimento dos estudos da linguagem, o novo contexto teórico-crítico que se firmou a partir de meados do século XX teve ampla repercussão nos diferentes campos do saber ocidental. A tradução, como veremos aqui, perdendo seu antigo caráter de tarefa secundária ou derivativa, passou então a ser entendida como um ato de leitura, sendo considerados os elementos envolvidos no processo, ou seja, apropriação, transposição e deformação 
e, por via de consequência, a recepção da obra traduzida. Entre outros aspectos, como bem destaca Antoine Berman, a disseminação e a recepção das obras literárias através dos tempos e lugares favoreceu a aproximação entre a crítica e a tradução, um acordo que tornou-se consubstancial ao ato de escrever. (2007, p.23).

A constatação de que grandes poetas da literatura ocidental também se dedicaram à tradução, sem dúvida, contribuiu para o reconhecimento de seu papel de mediadores entre diferentes culturas. Enfatizando que o campo de estudos comparatistas se definia no âmbito dos estudos da tradução - associados aos da recepção da obra, George Steiner destacava:

a questão de traduzir tem primordialidade em literatura comparada e é o que liga ao que eu considero como uma segunda meta nesses estudos: a disseminação e a recepção das obras literárias através dos tempos e lugares. ${ }^{1}$

Efetivamente, favorecendo o incremento dos estudos comparatistas, a tradução foi ampliando seu campo de ação abrindo-se a possibilidade de determinar flutuações da imagem de um escritor e de uma obra, bem como as possíveis modificações que um texto traduzido introduz em outra tradição literária.

Assim, quando a atenção se volta para literatura brasileira da segunda metade do século XIX, logo se evidencia a força da obra traduzida no período de formação de nossa literatura. Trata-se de um momento que, de certo modo, pode ser visto como o marco inicial do que só iria se consolidar um século mais tarde com a internacionalização do conceito de literatura. Conforme destaca Marie-Hélène Torres, as obras traduzidas certamente têm papel fundamental neste sentido, mas somente nas últimas décadas é que a tradução de obras brasileiras para o francês passa a ter um estatuto adequado, difundindo, não apenas a visão do outro, mas também construindo e projetando um imaginário mútuo. (2011, p 18). ${ }^{2}$

Apesar da independência, a cultura brasileira permaneceria atrelada ao modelo europeu. Assim, à época em que Machado de Assis começou a escrever, as traduções eram vistas como intermediárias entre aquele modelo e a cultura local. $\mathrm{Na}$ verdade, os tradutores procuravam adequar-se a seu duplo papel: manter os leitores em dia com a Europa, e, ao mesmo tempo, congregar os brasileiros em torno dos ideais comuns à nação que ainda estava em processo de formação. De certo modo, algumas dessas obras, mesmo traduzidas, não deixavam de contribuir para a afirmação da nacionalidade já que isto se dava pela inclusão de elementos da cultura local - aliás, uma atitude comum dos poetas desde o romantismo. O entusiasmo era geral e "quem não podia compor obra original contentava-se com traduzir as produções chegadas da Europa”, registra Mario de Alencar. (1960. v. 2. p.113; grifo nosso).

Estas considerações são fundamentais quando examinamos a atuação de Machado de Assis no cenário brasileiro de meados do século XIX - momento em que nossa literatura espelhava-se nas novidades que chegavam da França. A simples consulta a periódicos dessa época comprova isto e explica a familiaridade dos leitores brasileiros com a literatura francesa - uma situação que perduraria até o fim do

\footnotetext{
${ }^{1}$ Palavras proferidas em aula inaugural na Universidade de Oxford, em 1994 . Apud CARVALHAL, T. (2003, p. 235-6)

2 A pesquisa destaca as traduções de obras brasileiras para o francês em especial a partir ente 1970 , em estudo sobre a tradução de obras brasileiras para o francês. (2011, p. 18)
} 
século, tanto que em $O$ álbum, um hebdomadário dirigido por Artur Azevedo, é possível se encontrar poemas em francês assinados por escritores locais. ${ }^{3}$

O interesse do brasileiro por tudo que dizia respeito ao velho continente era reforçado pela presença francesa na cena teatral e isto se prolongaria por algum tempo. Como bem registra João Roberto Faria, se no período romântico essa presença tinha sido muito acentuada - notadamente os vaudevilles de Scribe - a mudança se processaria de modo lento. Entre 1865 e 1875

o Teatro Ginásio pôs em cena dezenas de pequenas comédias, e embora sua
preocupação maior fosse a comédia realista e o "drama moderno" - não o
romântico - predominaram traduções do francês. (grifo nosso) E os
espetáculos eram geralmente compostos de uma peça principal, mais longa, e
de uma pequena comédia. ${ }^{4}$ (1993. p 107-111).

Neste contexto era natural que a preocupação em difundir o que chegava de fora contasse com a contribuição de vários escritores: é o caso de Olavo Bilac, Rui Barbosa, Carlos de Laet, entre outros, que se dedicaram também à tradução. E como neste momento a intelectualidade, inclusive o jovem Machado de Assis, lutava pela criação de um teatro nacional, traduzir peças do repertório francês seria mais que o modo de preencher lacunas ante a crescente demanda pelo que vinha da Europa: as comédias francesas representavam a abertura de novos caminhos ante o esgotamento dos padrões românticos.

Ciente de que o conhecimento de obras de outras literaturas representava uma ampliação de horizontes para o público local, entre os anos 1859 e 1870, a par da crítica teatral, Machado dedica-se também à tradução. Pode-se mesmo dizer que as atividades de tradutor e crítico foram o marco inicial da carreira de escritor. E não há dúvida de que suas ideias representaram uma significativa contribuição para o teatro nacional - um teatro voltado para a educação do povo, em sintonia com as ideias modernas, da assim chamada "comédia burguesa," cujo referencial era a vida contemporânea.

Os pareceres emitidos na condição de membro do Conservatório Dramático comprovam que, para ele, traduzir era uma atividade séria. Diante das dificuldades inerentes ao processo, reconhecia que, em seu papel mediador, o tradutor devia vencer as barreiras linguísticas para conferir ao texto de chegada um sentido aceito pelos falantes locais. Não hesitava mesmo em condenar a atitude os tradutores que, de modo imediatista, visando tão somente a aclamação do público, tinham sempre à mão um sucesso europeu do momento a ser vertido à nossa língua. (MACHADO DE ASSIS, J.M., 1957, C. T. p. 20).

Seu empenho pela adequação do texto ao público da corte é visível. Se de um lado, estava atento para que as peças tivessem boa acolhida, de outro, sabia que a liberdade do tradutor era limitada pela língua e também pelas propriedades inerentes à forma dramática. A certo momento, chegou a tratar com ironia o tradutor de um drama que confessara ter introduzido mudanças substanciais no texto para descontrair

\footnotetext{
3 Trata-se de uma publicação que circulou no Rio e Janeiro entre 1893 e 1895 em que colaboravam autores iniciantes via de regra. O título decorria do fato de também serem publicadas imagens, o que era algo novo então.

${ }^{4}$ Cf. João R. Faria se forem somadas as peças do repertório francês às do repertório português, fica evidente a hegemonia na cena do Teatro Ginásio dos autores estrangeiros. Op.cit. p.109
} 
e, com isto, atenuar seu efeito dramático junto ao público. ${ }^{5}$ (MACHADO DE ASSIS, J.M. 1958. p. 136-137).

As traduções machadianas contemplaram desde poetas representativos do cânone dramático francês até autores populares naquela quadra do século. Lamentavelmente, apesar de intensas pesquisas bibliográficas, de modo especial as de J. Galante de Souza, muitas dessas traduções não foram encontradas, à exceção de Suplício de uma mulher e Hoje avental, amanhã luva - o que torna provisórias as observações sobre procedimentos do tradutor. ${ }^{6}$ Considerando alguns libretos de ópera e de poesia, Machado de Assis traduziu cerca de quinze peças de teatro, (algumas foram apenas encenadas). Assim, Queda que as Mulheres têm para os tolos tradução de De l'amour des femmes pour les sots, de Victor Héneau, publicada em Liège e Paris e inspirada em um texto do século XVIII, é seguida por Hoje Avental, Amanhã Luva, (Chasse au Lyon) de Vattier e Nanjac, Montjoye de Octave Feuillet e Suplício de uma mulher de Dumas Fils e Girardin. A partir de meados dessa década, colaborou em produções de caráter musical como $O$ barbeiro de Sevilha de Beaumarchais e o drama lírico-fantasioso $O$ remorso vivo, além de Cenas da vida do Rio de Janeiro (uma paródia da ópera La Traviata de Verdi, inspirada em A dama das camélias).

A prova de que seu interesse era amplo e permaneceria, mesmo após ser consagrado como poeta e romancista, é que não hesitou mais tarde em traduzir Les plaideurs de Racine (Os demandistas). Trata-se, como vemos, de um repertório heterogêneo, que vai do teatro clássico francês até autores populares naquela quadra do século, com suas comédias sentimentais ou vaudevilles. 7

Por serem desconhecidas circunstâncias que cercavam sua tarefa, não se discute suas escolhas, mas é importante destacar que a tradução dos textos escritos para o teatro, ao mesmo tempo em que proporcionava o contato direto com autores daquela quadra do século, foi um exercício de criação que certamente deixou marcas em sua obra. Este é o caso das duas comédias de sua lavra em que desenvolveu situações da comédia Alfred de Musset intitulada Il faut qu'une porte soit ouverte ou fermée (É necessário abrir ou fechar a porta). Com efeito, esta comédia-provérbio teria eco em peças do próprio Machado: a de estreia $O$ caminho da porta, levada à cena em 1863 e em Lição de botânica que, destaque-se, foi escrita em 1906.

Com apoio no princípio da verossimilhança, próprio da estética do classicismo francês - isto é, falar ao público diante do qual as peças eram representadas, suas peças invariavelmente fixavam um contexto familiar às plateias de então. Outra prova de que o escritor estava atento à recepção do texto pelo público brasileiro é o fato de tomar como referência o falar cotidiano dos frequentadores dos

\footnotetext{
${ }^{5}$ O tradutor admitiu mesmo que não hesitara em atenuar o efeito do texto: “meti-lhe o jocoso que não tinha.”, loc. cit.

${ }^{6}$ Existem ainda alguns manuscritos de comédias francesas entre as quais Os burgueses de Paris de Dumanoir, Clairville e Cordier e As mulheres de mármore de Barrière e Thiboust. Contrariamente ao que se pensou inicialmente, Machado não é o autor desta peça, mas sim seu tradutor. Cf. MASSA, J. M. A Juventude de Machado de Assis. Rio de Janeiro: Civilização Brasileira, 1971. p. 319.

7 Existem ainda alguns manuscritos de comédias francesas entre as quais Os burgueses de Paris de Dumanoir, Clairville e Cordier e As mulheres de mármore de Barrière e Thiboust.
} 
teatros cariocas. A transposição das falas dos personagens para nossa língua não se limitava à mera correspondência de palavras e expressões. ${ }^{8}$

Assim, o título da comédia Chasse au lion passou a Hoje avental, amanhã luva, sendo sustentado por uma réplica que ele acrescentou ao original. ${ }^{9}$ Se os títulos das peças de Molière Le malade imaginaire e Le médecin malgré lui passaram a $O$ doente imaginário e Médico à força, ele também não hesitava em fazer supressões ou acréscimos para obter o riso imediato do público. Eliminava por vezes ditos ou réplicas que não funcionariam diante da plateia local, tais como as alusões boulevardières à idade das mulheres ou certas recriminações a criados, como bem assinala Jean-Michel Massa. (1971, p. 19)

Bem mais que a busca de nacionalização, este esforço representava a intenção de situar a peça em um contexto familiar ao público do Teatro Ginásio. Prova disso é que a cena da peça se passa no Rio de Janeiro, e não em Paris, sendo marcada pela escolha de nomes típicos como o dos criados Rosinha e Bento, enquanto que Desmarais é a loja do perfumista da Rua do Ouvidor, então, o centro de convergência de uma sociedade afrancesada. O tradutor não hesitou em proceder a deformações no texto, introduzindo elementos do novo contexto. Assim, um tipo da comédia italiana, a serva padronna, deu lugar a serviçais representativos de um país em que as lides domésticas eram exercidas por escravos. Com razão, J-M. Massa afirma que essa comédia não foi apenas nacionalizada, mas machadizada.

O cotejo da peça Suplício de uma mulher com o original francês de 1865, confirma a posição de Machado de Assis sobre a tradução. A peça de Emile Giradin fora objeto de um sério desentendimento entre o autor e Alexandre Dumas Filho, pois ele solicitara a colaboração do jovem amigo, mas depois, discordando de algumas soluções, publicou-a apenas em seu nome. Machado comentou objetivamente este fato no Diário do Rio de Janeiro, por ocasião da estreia da peça, mas não deixou dúvida sobre sua própria posição já que transcreveu a defesa de Dumas, o que era um modo de destacar a co-autoria." ${ }^{10}$ O texto de saída para a tradução de Machado é o de M. Lévy, impresso em $1865 .{ }^{11}$ Nela mantém a estrutura e mesmo as didascálias dos atos e cenas; já as falas sofrem alterações significativas, em especial no que diz respeito à contextualização, um procedimento aproximado ao que fizera Dumas na versão questionada do texto .

De olhos atentos ao ambiente em que vivia - o que certamente frutificaria na obra de ficção posterior, o tradutor estava empenhado em adaptar o texto à nova situação, visando obter o efeito junto ao público da Corte. Estão neste caso escolhas lexicais que representam diferentes modos de aproximar as falas à situação em foco. Assim, para obter participação afetiva da plateia recorre a qualificativos típicos da nossa fala coloquial como "doida varrida” para o adjetivo folle (louca), e "passar a mão por cima”, para o verbo de ação gâter, no sentido de adular - além disso, em

\footnotetext{
${ }^{8}$ Segundo o crítico Jacques Scherer, a adaptação da peça ao público fazia-se permanentemente, (no original: "l'adaptation de la pièce au public se fait donc presque à chaque moment”). In: SCHERER J: La dramaturgie classique en France, p. 143.

${ }^{9}$ Nesta peça que foi levada no Teatro Odéon em maio de 1852, o tradutor teria introduzido profundas modificações, ficando a meio caminho entre a imitação e a adaptação. Cf. J-M. Massa. Dispersos de Machado de Assis. Introdução. Rio de Janeiro: MEC/INL, 1965, p. XXXVI et sqq.

${ }^{10}$ Na Edição Jackson, é possível acompanhar essa discussão pois são transcritas as cartas trocadas entre os autores Cf. MACHADO DE ASSIS. Teatro. p. 409-428.

${ }^{11}$ Em gallica.bnf.fr, tem-se acesso a uma edição de 1865, dada como a $3^{\mathrm{a}}$. Assim são levadas em conta: a peça de Emile Girardin de 1863, a de Alexandre Dumas Fils e a tradução de Machado de Assis.
} 
lugar da conjunção ‘desde que’ prefere a oralidade da expressão “dês que”. O esforço de contextualização fica mais evidente quando se vale da expressão "eu vou ver o que há na praça”, faz referência à Bourse (a Bolsa de valores parisiense), certamente uma forma mais familiar a ouvidos brasileiros. O exame atento de seu procedimento confirma que Machado estava consciente de que traduzir implicava permanente busca de adequação do texto à nova situação.

Embora sem a pretensão de esgotar aqui os procedimentos de Machado de Assis, julga-se ter ficado claro que o ato de traduzir para ele implicava a captação de sentido do texto de partida, bem como à recepção do novo texto, vale dizer aos receptores que viviam em outro contexto, mais especificamente aos frequentadores do Teatro Ginásio. E assim, graças a um bom domínio da língua e da literatura francesas, suas traduções fortaleceram o diálogo intertextual com a comédia burguesa da época em que deu início à sua carreira.

Sua atuação não estava distante da que destaca Tania F. Carvalhal quando estuda a tradução como disciplina institucionalizada: o tradutor é um intermediário exemplar que torna possível o conhecimento não apenas de uma literatura engendrada em outra língua, mas também dos costumes e dados culturais veiculados pelo texto traduzido. (2003, p. 238)

Como se vê, apesar dos estreitos limites teóricos de sua época, o jovem Machado ele intuiu que ler é transferir sentidos, reconhecendo uma alteridade, por isto não se limitava à substituição literal das falas dos personagens do texto de origem. Dominando os princípios da linguagem dramática e sempre atento às equivalências semânticas, suas traduções se aproximavam do falar cotidiano de seu tempo, certamente o modo de obter boa acolhida das plateias cariocas, e correspondiam ao empenho pela consolidação do teatro brasileiro. Estava ciente de que o papel do tradutor não deveria se restringir aos elementos estritamente linguísticos: antecipandose a proposições de teóricos do século XX que, como destaca Umberto Eco, sublinharam a importância dos elementos culturais; ${ }^{12}$ suas estratégias já anunciavam 0 que hoje é consensual: a tradução tem lugar de destaque nas mediações interliterárias, confirmando-se a contribuição decisiva da tarefa do tradutor para a disseminação da obra traduzida, em especial para assegurar a recepção de textos de outras culturas pelo leitor. Ou pelos espectadores dos teatros de sua época.

Helena Fava Tornquist heltorn@cpovo.net Universidade Federal de Santa Catarina

\footnotetext{
${ }^{12}$ Sublinhando que a tradução não é a mera passagem entre duas línguas, mas duas culturas,destaca a posição de autores como Snell Hornby, Lefèvere e S. Bassnet. (2007, p. 190)
} 


\section{Referências}

ALENCAR, Mario de. O Teatrólogo. In: MACHADO DE ASSIS, J.M. Obra Completa. Rio de Janeiro: Aguilar, 1960. v. 2., p.1136.

BERMAN, Antoine. A tradução e a letra: ou o albergue do longínquo. Trad. de Marie-Hélène Catherine Torres, Mauri Furlan, Andréia Guerini. Rio de Janeiro: 7Letras. 2007.

CARVALHAL, Tania Franco. O próprio e o alheio. São Leopoldo: UNISINOS, 2003.

CHEVREL, Yves. La littérature comparée. Paris: PUF, 1989, p 18-9.

ECO, Umberto. Quase a mesma coisa. Experiências de tradução. Trad. de Eliana Aguiar. São Paulo: Record, 2007.

FARIA, João Roberto. O teatro realista na Brasil: 1855-1865. São Paulo: Perspectiva, 1993.

GIRARDIN, Émile de. Le supplice d'une femme. http://www.gallica. bnf. fr.Acesso12 de novembro de 2005.

MACHADO DE ASSIS, Joaquim Maria. Crônicas: Rio de Janeiro: Jackson, 1957.

MACHADO DE ASSIS, Joaquim Maria. Teatro: Rio de Janeiro: Jackson, 1957.

MACHADO DE ASSIS, Joaquim Maria. Dispersos de Machado de Assis. Coligidos e anotados por Jean-Michel Massa. Rio de Janeiro: MEC/INL, 1965.

MAGALHÃES Jr., Raymundo. Ao redor de Machado de Assis: pesquisas e interpretações. Rio de Janeiro: Civilização Brasileira, 1958.

MASSA, Jean-Michel. A juventude de Machado de Assis. (1839-1870): Ensaio de biografia intelectual. Rio de Janeiro: Civilização Brasileira, 1971.

MINISTÉRIO DA EDUCAÇÃO. Revista do Livro. Jun. 1956, v.1. p. 178-192. Pareceres emitidos por Machado de Assis. SCHERER, Jacques. La dramaturgie classique en France. Paris, Nizet s/d

TORRES, Marie-Hélène. As traduções e seu funcionamento nas culturas. In: FALEIROS, Álvaro et al. A tradução de obras francesas no Brasil. Rio de Janeiro: Annablume, 2011. 